\title{
Lung cancer-associated transcript 1 facilitates tumorigenesis in laryngeal squamous cell carcinoma through the targeted inhibition of miR-493
}

\author{
ZHEN ZHAO $^{1 *}$, YAN XING $^{2 *}$, YAN LIU $^{1}$ and SHANGHUA JING ${ }^{1}$ \\ ${ }^{1}$ Department of Otorhinolaryngology-Head and Neck Surgery, The Fourth Hospital of Hebei Medical University, \\ Shijiazhuang, Hebei 050011; ${ }^{2}$ The Third Department of Rehabilitation, Shijiazhuang No. 1 Hospital, \\ Shijiazhuang, Hebei 050000, P.R. China
}

Received April 15, 2020; Accepted July 7, 2020

DOI: $10.3892 / \mathrm{mmr} .2020 .11697$

\begin{abstract}
Long non-coding RNAs (lncRNAs) serve important roles in the tumorigenesis of a diverse range of cancer types. The lung cancer-associated transcript 1 (LUCAT1), has been reported to promote the proliferation, migration and invasion of oral squamous cell carcinoma cells. However, the exact role of LUCAT1 in laryngeal squamous cell carcinoma (LSCC) remains to fully understood. The present study aimed to interrogate the role and modulatory mechanism of LUCAT1 in LSCC. Reverse transcription-quantitative PCR and western blotting were used to investigate the expression of LUCAT1 and miR-493, as well as the protein expression of cyclin-dependent kinase 2, cyclin E1, p21, matrix metalloproteinase (MMP)2, MMP9, vascular endothelial growth factor-C, Bcl-2, Bax, cleaved caspase-3 and procaspase- 3 . Cell Counting Kit-8, flow cytometry, wound healing and Transwell assays were performed to analyze the proliferation, cell cycle, apoptosis levels, and the migratory and invasive abilities, respectively, of the LSCC AMC-HN-8 cell line. In addition, dual-luciferase reporter and ribonucleoprotein immunoprecipitation assays were used to investigate the binding between LUCAT1 and microRNA (miR)-493. The results of the present study revealed that the expression levels of LUCAT1 were upregulated in AMC-HN-8 cells. The genetic knockdown of LUCAT1 expression levels significantly suppressed the cell proliferation, alongside downregulating the expression levels of CDK 2 and cyclin E1 and upregulating p21 expression levels. In addition, the knockdown of LUCAT1 inhibited cell migration
\end{abstract}

Correspondence to: Dr Shanghua Jing or Dr Zhen Zhao, Department of Otorhinolaryngology-Head and Neck Surgery, The Fourth Hospital of Hebei Medical University, 12 Jiankang Road, Shijiazhuang, Hebei 050011, P.R. China

E-mail: jingshanghua22@163.com

E-mail: zhaozhenn11@163.com

*Contributed equally

Key words: lung cancer-associated transcript 1, microRNA-493, squamous cell carcinoma of the larynx, tumorigenesis and invasion, as demonstrated using the wound healing and Transwell assays, respectively. Moreover, LUCAT1 knockdown promoted cell apoptosis and upregulated the expression levels of Bax and cleaved caspase-3, whilst downregulating the expression levels of Bcl-2. Furthermore, LUCAT1 was discovered to directly bind to and inhibit the well-known tumor suppressor, miR-493. Notably, the specific inhibition of miR-493 partly blocked the anticancer effects of LUCAT1 knockdown in AMC-HN-8 cells. In conclusion, these results suggested that LUCAT1 may facilitate tumorigenesis in LSCC through the targeted inhibition of miR-493, which provides evidence for a novel target for the treatment of LSCC.

\section{Introduction}

Laryngeal carcinoma is a common type of head and neck squamous cell carcinoma (SCC), ranking as the sixth most commonly diagnosed carcinoma worldwide (1). The majority (95\%) of laryngeal carcinoma cases are SCCs (2). Laryngeal SCC (LSCC) is the most common primary malignant tumor affecting the laryngeal framework (3). The disease presents with a poor prognosis, due to the frequent late diagnosis and lymph metastasis of the disease (4), which can at least partly be attributed to poor understanding of the molecular mechanisms underlying its development. Habitual alcohol intake and tobacco use are known risk factors for LSCC, representing a major health hazard for humans (5). There is currently no effective treatment for LSCC (6).

A large number of long non-coding RNAs (lncRNAs) have been reported to serve important roles in tumorigenesis (7-9). Lung cancer-associated transcript 1 (LUCAT1), also known as the smoke and cancer-associated lncRNA-1 (SCAL1), is encoded by the RNA gene located on chromosome $5 \mathrm{q} 14.3$, and was first identified as a lncRNA overexpressed in lung cancer cells (10). Previous studies have provided evidence of the protumorigenic role of LUCAT1 in a variety of types of cancer, including oral SCC, breast, colorectal, papillary thyroid and ovarian cancers (11-15). However, the possible role of LUCAT1 in the development or progression of LSCC remains to be determined.

MicroRNAs (miRs/miRNAs) are another subgroup of non-coding RNAs that interact with lncRNAs to regulate 
biological processes, including proliferation, apoptosis and motility (16). Previous studies have demonstrated that LUCAT1 promoted the growth, migration and invasion of cancer cells through the targeted modulation of certain miRNAs, including miR-5720 and miR-5582 $(17,18)$. miR-493 was previously reported to serve as a tumor suppressor in hepatic and pancreatic cancer (19-21); however, whether and how miR-493 is involved in LSCC remains unclear. Thus, the present study aimed to investigate the potential interaction of LUCAT1 with miR-493 and to determine their effects on LSCC cellular activities, such as cell proliferation, migration, invasion and apoptosis.

\section{Materials and methods}

Cell culture. The normal nasopharyngeal epithelial NP69 cell line and the corresponding LSCC cancer cell lines AMC-HN-8, Tu177, Tu686 and M4e were obtained from The Cell Bank of Type Culture Collection of the Chinese Academy of Sciences (22). All cells were cultured in the DMEM (Gibco; Thermo Fisher Scientific, Inc.) supplemented with 10\% FBS (Gibco; Thermo Fisher Scientific, Inc.), and maintained at $37^{\circ} \mathrm{C}$ and $5 \% \mathrm{CO}_{2}$.

Prediction of target genes. To further investigate the molecular mechanisms underlying the role of LUCAT1 in the tumorigenesis of LSCC, the Encyclopedia of RNA Interactomes (ENCORI) database (http://starbase.sysu.edu.cn) was used. ENCORI is an open-source platform for studying the miRNA-ncRNA (23), miRNA-mRNA, ncRNA-RNA, RNA-RNA, RBP-ncRNA and RBP-mRNA interactions from CLIP-sequencing, degradome-sequencing and RNA-RNA interactome data.

Knockdown plasmids. Two short hairpin RNAs (shRNAs) against LUCAT1 (shRNA-LUCAT1-1 and shRNA-LUCAT1-2; $500 \mathrm{ng} / \mu \mathrm{l}$ ) from Guangzhou RiboBio Co., Ltd. were used for the specific knockdown of LUCAT1, with use of shRNA containing nonsense shRNA sequences as negative control (shRNA-NC; $500 \mathrm{ng} / \mu \mathrm{l}$ ). Two miR-493 inhibitors (miR-493 inhibitor-1 and miR-493 inhibitor-2; 100 pmol) and their negative control miR-NC (100 pmol) were purchased from Shanghai GenePharma Co., Ltd. All shRNAs and inhibitors were separately transfected into AMC-HN- 8 cells $\left(1 \times 10^{5}\right.$ cells/well) using Lipofectamine ${ }^{\circledR} 2000$ reagent (Invitrogen; Thermo Fisher Scientific, Inc.) at $37^{\circ} \mathrm{C}$. Subsequent assays were performed at $24 \mathrm{~h}$ after transfection.

Reverse transcription-quantitative PCR (RT-qPCR). Total RNA was gained from cell samples. First, it was extracted via TRIzol ${ }^{\circledR}$ reagent (Thermo Fisher Scientific, Inc.) and then reverse-transcribed into cDNA using a RevertAid ${ }^{\mathrm{TM}}$ cDNA Synthesis kit from Takara Bio, Inc at $42^{\circ} \mathrm{C}$ for $1 \mathrm{~h}$ and $90^{\circ} \mathrm{C}$ for just $5 \mathrm{~min}$. The SYBR Premix Ex Taq ${ }^{\mathrm{TM}}$ II kit (Thermo Fisher Scientific, Inc.) was applied for $\mathrm{qPCR}$. The PCR reaction mixture contained included $3 \mathrm{mM} \mathrm{MgCl}_{2}, 0.5 \mu \mathrm{M}$ forward and reverse primers, $2 \mu \mathrm{l}$ SYBR Green PCR master mix and $2 \mu \mathrm{l}$ cDNA. Samples were run on a QuantStudio 3 Real-Time PCR system (Applied Biosystems; Thermo Fisher Scientific, Inc.). Thermocycling conditions of the qPCR were: 5 min at $95^{\circ} \mathrm{C}$, with 40 cycles for $30 \mathrm{sec}$ at $95^{\circ} \mathrm{C}$ and $45 \mathrm{sec}$ at $65^{\circ} \mathrm{C}$. Relative expression levels were calculated using the $2^{-\Delta \Delta \mathrm{Cq}}$ method and normalized to the internal reference genes
GAPDH or U6 (24). The primers were as follows: LUCAT1 forward, 5'-AGCTCCACCTCCCGGGTTCACG-3' and reverse, 5'-CGTGAACCCGGGAGGTGGAGCT-3'; miR-493 forward, 5'-TTGTACATGGTAGGCTTTCATT-3' and reverse, 5'-AAC CATTTATTTCTCCCGACC-3; GAPDH forward, 5CACATC GCTCAGACACCATG-3' and reverse, 5'-TGACGGTGCCAT TGGAATTT-3'; U6 forward, 5'-CTCGCTTCGGCAGCACAT ATA-3' and reverse, 5'-ACGCTTCACGAATTTGAGTGTC-3'.

Cell Counting Kit-8 (CCK-8) assay. Cell proliferation was analyzed using a CCK-8 assay kit following the manufacturer's manual. An AMC-HN-8 cell suspension ( $5 \times 10^{3}$ cells/well) was plated into a 96-well plate and incubated for $24 \mathrm{~h}$ at $37^{\circ} \mathrm{C}$. Following the incubation, $10 \mu \mathrm{lCCK}-8$ solution was added into each well after transfection and incubated for $4 \mathrm{~h}$ at $37^{\circ} \mathrm{C}$. The absorbance was measured at a wavelength of $450 \mathrm{~nm}$ using a microplate reader (Synergy2; BioTek Instruments, Inc.).

Flow cytometric analysis of the cell cycle and apoptosis. For cell cycle analysis, AMC-HN-8 cells were collected in a flow cytometry tube centrifuged at $850 \mathrm{xg}$ at $4^{\circ} \mathrm{C}$ for $10 \mathrm{~min}$, washed in PBS and fixed in cold $70 \%$ ethanol for $30 \mathrm{~min}$ at $4^{\circ} \mathrm{C}$. After washing in PBS, the samples were centrifuged at $850 \mathrm{xg}$ at $4^{\circ} \mathrm{C}$ for $10 \mathrm{~min}$. The pellets were treated with $0.5 \mathrm{ml}$ ribonuclease and incubated with propidium iodide (Beyotime Institute of Biotechnology) for $30 \mathrm{~min}$ at $37^{\circ} \mathrm{C}$. The cells were measured at an emission wavelength of $605 \mathrm{~nm}$ for the forward and side scatters to identify single cells. For cell cycle analysis, the number of cells in either the $\mathrm{S}$ or G1 phase was counted using an algorithm to fit Gaussian curves to each phase (ModFit LT, Version of 4.0).

For the analysis of cell apoptosis, an Apoptosis Detection kit (Beyotime Institute of Biotechnology) was used. The cells were collected by centrifugation at $850 \mathrm{x} \mathrm{g}$ at $4^{\circ} \mathrm{C}$ for $5 \mathrm{~min}$, re-suspended in a binding buffer (195 $\mu \mathrm{l})$ containing $1 \%$ Annexin V-FITC $(5 \mu \mathrm{l})$ and 1\% PI $(10 \mu \mathrm{l})$, and incubated at room temperature for $5 \mathrm{~min}$ in the dark. Data were acquired using a flow cytometer (Accuri C6; BD Biosciences) and analyzed using FlowJo (version of 7.6.5; FlowJo LLC).

Western blotting. Cells were harvested and total protein was extracted using RIPA lysis buffer (Beyotime Institute of Biotechnology) with protease inhibitor added to the lysis buffer (Beyotime Institute of Biotechnology; 1:100). The lysates were centrifuged at $4^{\circ} \mathrm{C}$ at $850 \mathrm{x} \mathrm{g}$ for $15 \mathrm{~min}$. The supernatant was collected and mixed with a loading buffer (Beyotime Institute of Biotechnology) containing $100 \mathrm{mM}$ dithiothreitol. Western blotting was subsequently performed, as previously described (25). Briefly, total protein was quantified using Protein Concentration Determination kit (Beyotime Institute of Biotechnology) and proteins (30 $\mu \mathrm{g} / \mathrm{lane})$ were separated by SDS-PAGE using $15 \%$ gels. The separated proteins were subsequently transferred onto PVDF membranes (EMD Millipore) and blocked with 5\% BSA (Beyotime Institute of Biotechnology) at room temperature for $2 \mathrm{~h}$. The membranes were then incubated with the following primary antibodies (Abcam) at $4^{\circ} \mathrm{C}$ overnight: Anti-CDK2 (cat. no. ab32147; 1:1,000 dilution), anti-cyclin E1 (cat. no. ab33911; 1:1,000 dilution), anti-p21 (cat. no. ab109520; 1:1,000 dilution), anti-matrix metallopeptidase (MMP)2 (cat. no. ab97779; 1:1,000 dilution), anti-MMP9 (cat. no. ab38898; 1:1,000 
dilution), anti-vascular endothelial growth factor (VEGF)-C (cat. no. ab9546; 1:1,000 dilution), anti-Bcl-2 (cat. no. ab32124; 1:1,000 dilution), anti-Bax (cat. no. ab32503; 1:1,000 dilution), anti-cleaved caspase-3 (cat. no. ab2302; 1:1,000 dilution), anti-pro caspase-3 (cat. no. ab32150; 1:1,000 dilution) and anti-GAPDH (cat. no. ab8245; 1:2,000 dilution). Following the primary antibody incubation, the membranes were washed with TBS with $0.1 \%$ Tween-20 and incubated at room temperature for $1.5 \mathrm{~h}$ with a horseradish peroxidase-conjugated goat anti-rabbit IgG secondary antibody (1:5,000; SA00001-9; ProteinTech Group, Inc.) or goat anti-mouse IgG secondary antibody (1:5,000; SA00001-8; ProteinTech Group, Inc.). Protein bands were visualized using a luminol reagent (Santa Cruz Biotechnology, Inc.) and analyzed using ImageJ software (version 1.48; National Institutes of Health).

Wound healing assay. AMC-HN-8 cells were cultured in six-well plates $\left(6 \times 10^{4}\right.$ cells/well) and transiently transfected with specific plasmids. Following $24 \mathrm{~h}$ of transfection, a linear scratch was created in the cell monolayer using a $200-\mu 1$ pipette tip. The cells were subsequently cultured under standard conditions in serum-free medium (Gibco; Thermo Fisher Scientific, Inc.) at $37^{\circ} \mathrm{C}$ in $5 \% \mathrm{CO}_{2}$. Using ImageJ software (version 1.8.0; National Institutes of Health) to calculate the wound width. Images of the wound were captured at $72 \mathrm{~h}$ using a light microscope (Nikon Corporation), magnification, x100.

Transwell invasion assay. A Transwell invasion assay was used to analyze the invasive rate of cells. Briefly, AMC-HN- 8 cells in $100 \mu \mathrm{l}\left(2 \times 10^{5}\right)$ serum-free medium (Thermo Fisher Scientific, Inc.) were plated into the upper chambers of an $8-\mu \mathrm{m}$ Transwell plate (Corning,Inc.) precoated with Matrigel ${ }^{\mathrm{TM}}$ (BD Biosciences) for $24 \mathrm{~h}$ at $37^{\circ} \mathrm{C}$ after transfection. RPMI-1640 medium containing $20 \%$ FBS was plated in the lower chamber to serve as a chemoattractant. Following $24-\mathrm{h}$ incubation at $37^{\circ} \mathrm{C}$, the invading cells on the bottom surface of the filter were fixed with $100 \%$ methanol at $4^{\circ} \mathrm{C}$ for $30 \mathrm{~min}$ and stained with hematoxylin at room temperature for $20 \mathrm{~min}$. Cell invasion was analyzed in three randomly selected fields under a fluorescence microscope (magnification, $\mathrm{x} 20$ ).

Dual-luciferase reporter assay. The firefly luciferase reporter plasmid (pGL3-promoter vector; E1761; Promega) and constitutively active Renilla luciferase control plasmid pRL-TK (pmiR-RB-Report ${ }^{\mathrm{TM}}$, Beijing Baiaolaibo Technology Co., Ltd.) were used. The LUCAT1-3'-untranslated region (UTR) was cloned into the pGL3-promoter vector to generate wild-type (WT) LUCAT1-Luc. A mutant (MUT) LUCAT-1 3'-UTR was cloned into the pGL3-promoter vector to generate MUT LUCAT1-Luc by site-directed mutagenesis (QuikChange Lightning Site-Directed Mutagenesis kit; Agilent Technologies, Inc.). A plasmid containing an miR-493 mimic (5'-UGAAGG UCUACUGUGUGCCAGG-3') was purchased from Shanghai GenePharma Co., Ltd. or empty vector control was co-transfected using the Lipofectamine ${ }^{\circledR} 3000$ transfection reagent (Invitrogen; Thermo Fisher Scientific, Inc.) with the WT or MUT LUCAT1-Luc into AMC-HN-8 cells and incubated for $48 \mathrm{~h}$ at $37^{\circ} \mathrm{C}\left(1.5 \times 10^{5}\right.$ cells/well $)$. The cells were washed with PBS and lysed with RIPA lysis solution (Beyotime Institute of Biotechnology). The relative luciferase activity was analyzed

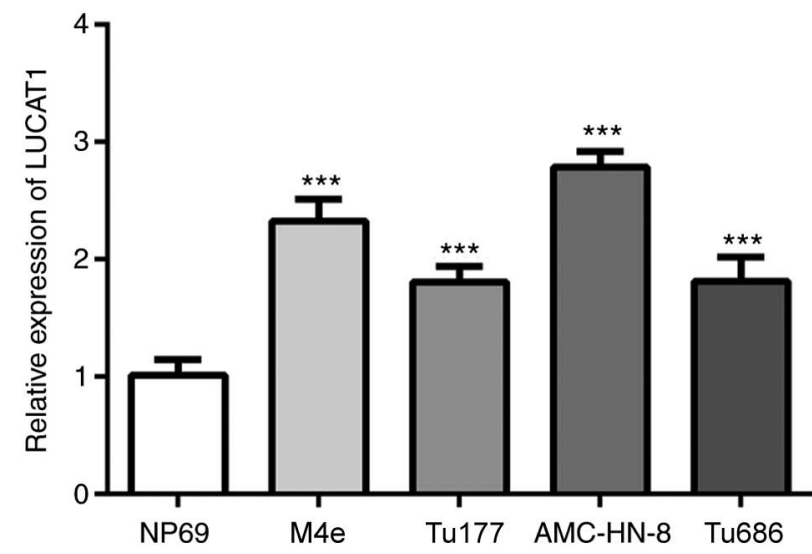

Figure 1. Upregulated expression levels of LUCAT1 in LSCC cells. Reverse transcription-quantitative PCR analysis of LUCAT1 expression levels in four LSCC cell lines (AMC-HN-8, Tu177, Tu686 and M4e) and one normal nasopharyngeal epithelial cell line NP69. ${ }^{* * *} \mathrm{P}<0.001$, vs. NP69. LUCAT1, lung cancer-associated transcript 1 ; LSCC, laryngeal squamous cell carcinoma.

using a plate reader at $410 \mathrm{~nm}$ (BD Biosciences) and normalized to the activity of a Renilla luciferase activity kit (pRL-TK; Beijing Baiaolaibo Technology Co., Ltd.). All procedures were performed according to the manufacturers' protocols.

Ribonucleoprotein immunoprecipitation (RIP) assay. A total of $1 \times 10^{7}$ AMC-HN- 8 cells were added to $2 \mathrm{ml}$ PBS (Beyotime, China) to wash, and centrifuged at $850 \mathrm{xg}$ at room temperature for $5 \mathrm{~min}$ to collect the cells. A RIP assay was performed using a Millipore Magna RIP ${ }^{\mathrm{TM}}$ RNA-Binding Protein Immunoprecipitation kit (Active Motif, Inc.), according to the manufacturer's protocol. Briefly, AMC-HN-8 cells were lysed with anti-EZH2 or IgG antibody at $4^{\circ} \mathrm{C}$ for $6 \mathrm{~h}$. A protein-RNA complex was captured and digested with $0.5 \mathrm{mg} / \mathrm{ml}$ proteinase $\mathrm{K}$ containing $0.1 \%$ SDS to extract RNA. RNA was extracted using TRIzol ${ }^{\circledR}$ reagent (Invitrogen; Thermo Fisher Scientific, Inc.) and RT-qPCR analysis was performed to analyze the expression levels of LUCAT1 and miR-493.

Statistical analysis. All experiments were repeated three times. Statistical analysis was performed using GraphPad Prism 5 software (GraphPad Software, Inc.) and all data are presented as the mean \pm SEM, unless otherwise specified. Statistical differences between 2 groups were determined using an unpaired two-tailed Student's t-test, while a one-way or two-way ANOVA followed by Tukey's post hoc test were used to analyze data with $>2$ groups. $\mathrm{P}<0.05$ was considered to indicate a statistically significant difference.

\section{Results}

LUCAT1 expression levels are upregulated in LSCC cells. The expression levels of LUCAT1 in the nasopharyngeal epithelial NP69 (normal) cell line, and LSCC cell lines AMC-HN-8, Tu177, Tu686 and M4e were analyzed. The expression levels of LUCAT1 were significantly upregulated in the LSCC cells compared with the NP69 cells, with the most prominent upregulation being observed in the AMC-HN-8 cells (Fig. 1A). Thus, the AMC-HN-8 cell line was used as the LSCC cell model in subsequent experiments. 

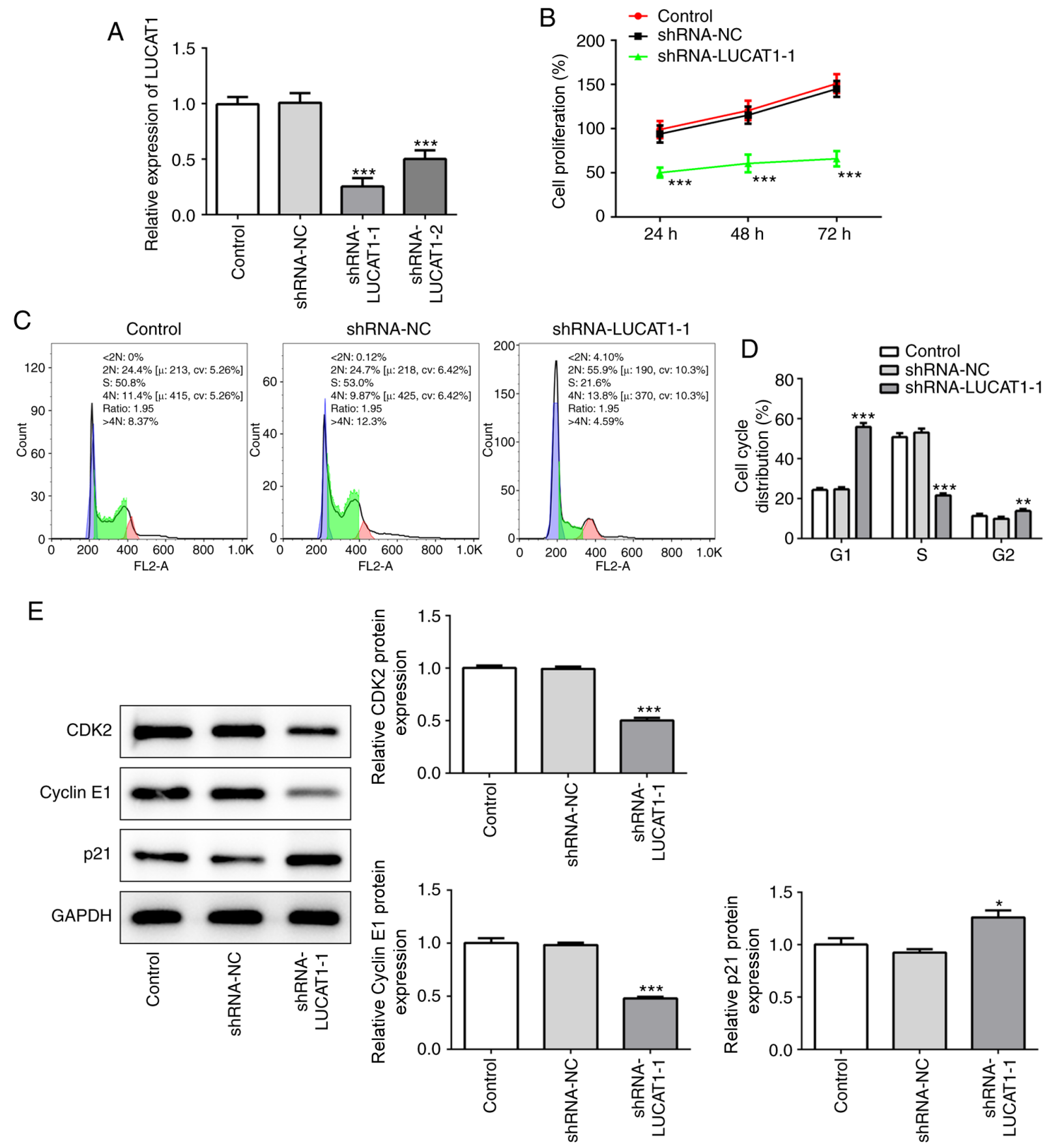

Figure 2. Inhibition of LUCAT1 suppresses cell proliferation. (A) Transfection efficiency of shRNA-LUCAT1-1/2 in AMC-HN-8 cells was analyzed using reverse transcription-quantitative PCR. (B) Cell proliferation of AMC-HN-8 cells transfected with shRNA-LUCAT1-1 was analyzed using a Cell Counting Kit-8 assay. (C) Flow cytometric analysis of cell cycle distribution of AMC-HN-8 cells transfected with shRNA-LUCAT1-1. (D) Quantification of cell cycle distribution from part (C). (E) Western blotting analysis of the expression levels of CDK2, cyclin E1 and p21 in AMC-HN-8 cells transfected with shRNA-LUCAT1-1. ${ }^{*} \mathrm{P}<0.05,{ }^{* *} \mathrm{P}<0.01,{ }^{* * *} \mathrm{P}<0.001$, vs. shRNA-NC group. LUCAT1, lung cancer-associated transcript 1 ; shRNA, short hairpin RNA; NC, negative control.

LUCAT1 knockdown suppresses the proliferation of LSCC cells. To determine how LUCAT1 affects LSCC, LUCAT1 expression levels were knocked down in AMC-HN-8 cells using shRNA. Out of the two shRNAs used, shRNA-LUCAT1-1 exhibited an enhanced knockdown efficiency (Fig. 2A); the expression levels of LUCAT1 were significantly downregulated in both the shRNA-LUCAT1-1- and shRNA-LUCAT1-2-transfected cells compared with the shRNA-NC group, but to a greater extent in shRNA-LUCAT1-1-transfected cells. Therefore, shRNA-LUCAT1-1 was used for further experiments.
The genetic knockdown of LUCAT1 significantly decreased the cell proliferation rate of AMC-HN-8 cells compared with untransfected AMC-HN-8 cells (referred to as control), which was determined using a CCK-8 assay (Fig. 2B). Moreover, compared with the control shRNA-LUCAT1-1 also significantly decreased the percentage of cells in the $S$ phase of the cell cycle, while significantly increasing the number of G1 phase cells (Fig. 2C and D), indicating that LUCAT1 knockdown may suppress the proliferation of cancer cells. Consistent with this hypothesis, shRNA-LUCAT1-1 was discovered to significantly downregulate the expression 

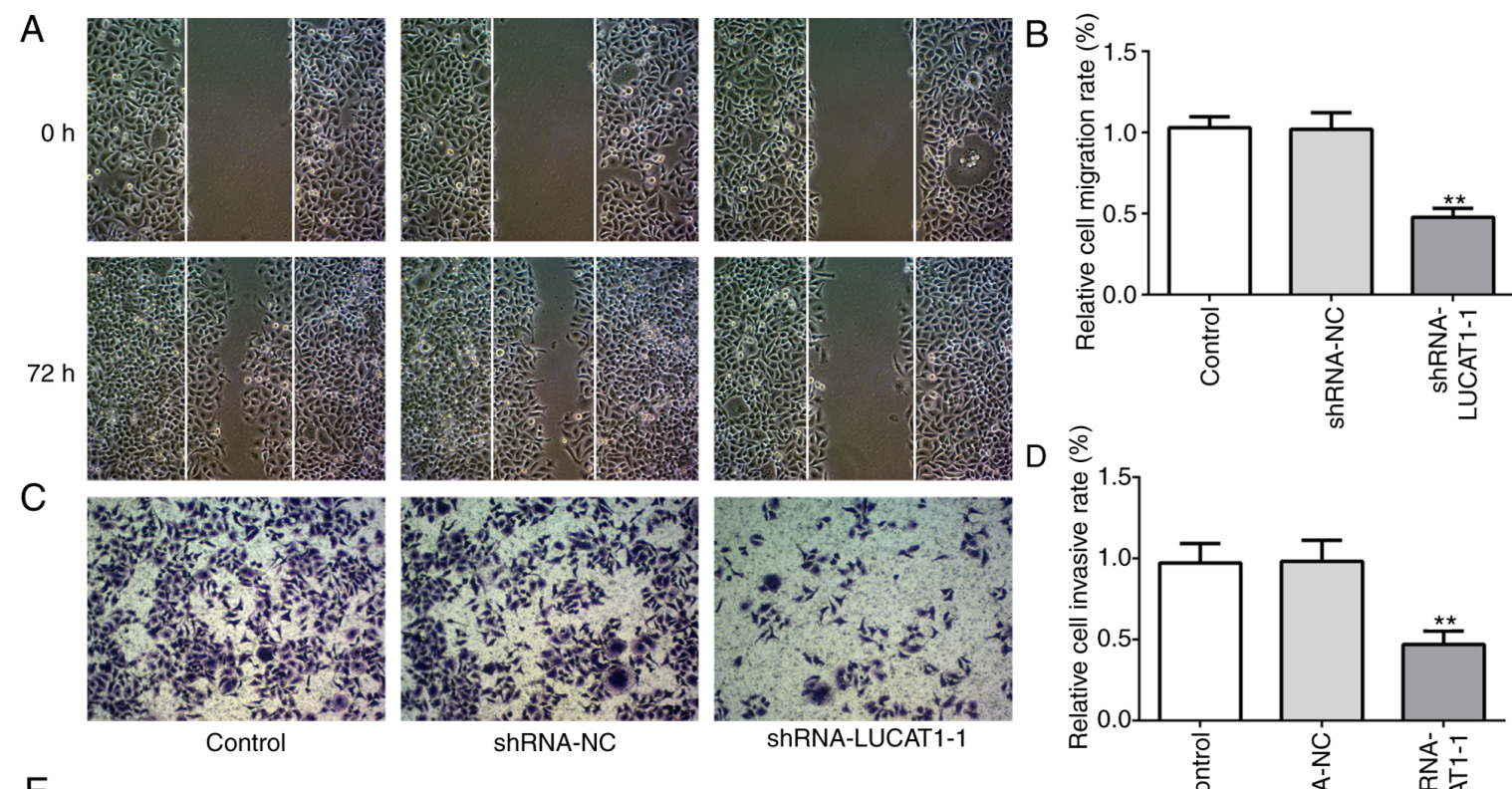

$E$
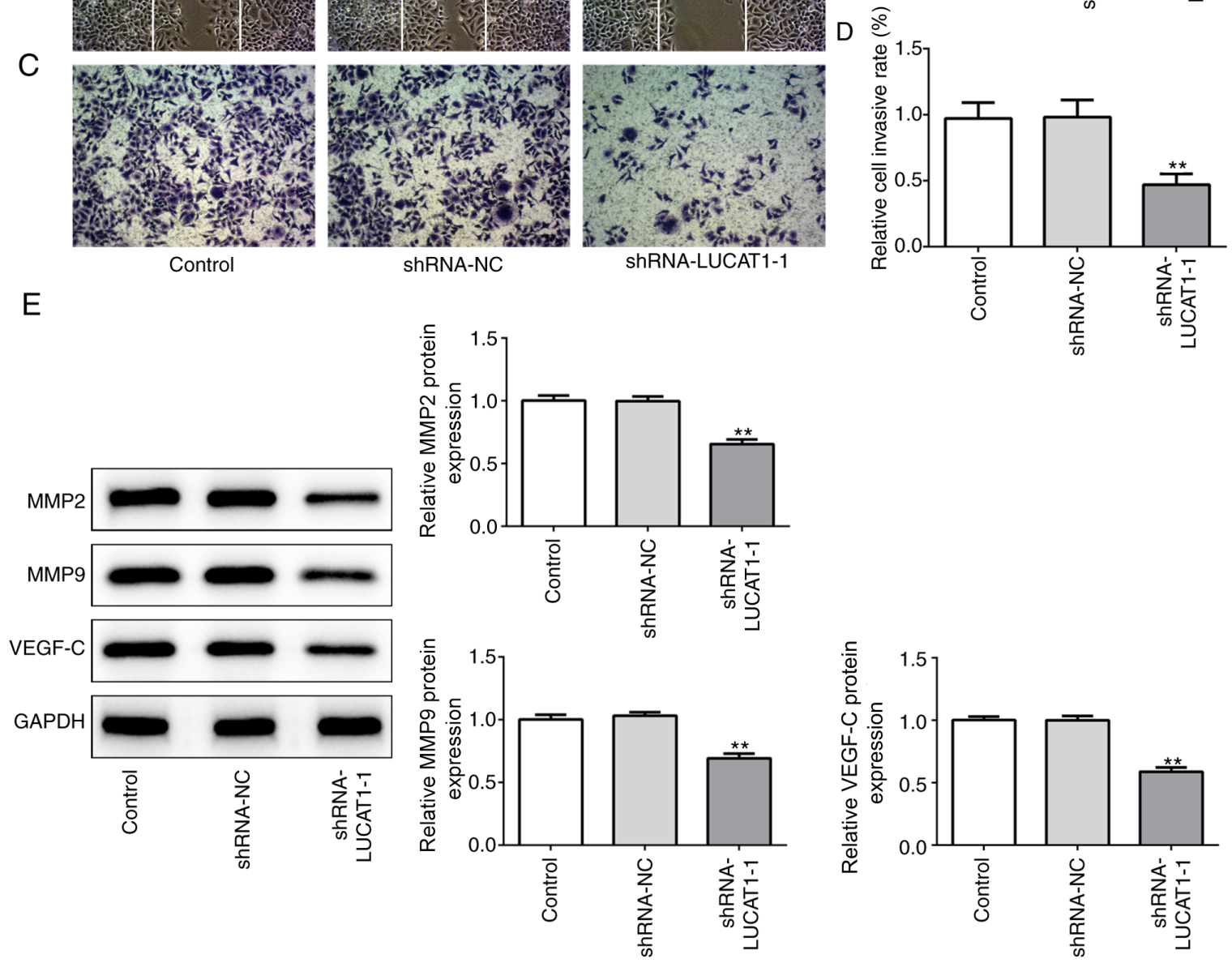

Figure 3. Inhibition of LUCAT1 suppresses cell migration and invasion. (A) Cell migration rate was analyzed in AMC-HN-8 cells transfected with shRNA-LUCAT1-1, magnification x100. (B) Semi-quantification of the relative cell migration rate from part (A). (C) Cell invasion rate was analyzed in AMC-HN-8 cells transfected with shRNA-LUCAT1-1, magnification x100. (D) Semi-quantification of the relative cell invasive rate from part (C). (E) Expression levels of the migration-associated proteins MMP2, MMP9 and VEGF-C were analyzed using western blotting. ${ }^{* *} \mathrm{P}<0.01$, vs. shRNA-NC group. LUCAT1, lung cancer-associated transcript 1; shRNA, short hairpin RNA; NC, negative control; MMP, matrix metallopeptidase; VEGF-C, vascular endothelial growth factor-C.

levels of CDK2 and cyclin E1 compared with the control and shRNA-NC (Fig. 2E), two proteins which facilitate cell cycle progression $(26,27)$, while significantly upregulating the expression levels of p21 compared with the control and shRNA-NC, a cell cycle inhibitor (28) (Fig. 2E). Therefore, these findings suggested that LUCAT1 may exert a suppressive effect on cell proliferation.

LUCAT1 knockdown inhibits the migration and invasion of LSCC cells. The effects of the knockdown of LUCAT1 on the migration and invasion of AMC-HN-8 cells was subsequently investigated. Compared with the control and shRNA-NC, LUCAT1 knockdown significantly suppressed the migration (Fig. 3A and B) and invasion (Fig. 3C and D) of LSCC cells, as observed using a wound healing or Transwell assay, respectively. In addition, shRNA-LUCAT1-1 significantly downregulated the expression levels of the migration-associated proteins, VEGF-C, MMP2 and MMP9 compared with the control and shRNA-NC (Fig. 3E). These data suggested that the knockdown of LUCAT1 may inhibit LSCC cell migration and invasion.

LUCAT1 knockdown promotes the apoptosis of LSCC cells. Compared with the control and shRNA-NC, LUCAT1-1 knockdown also significantly promoted the apoptosis of cancer cells (Fig. 4A). Furthermore, compared with the control and shRNA-NC, the knockdown of LUCAT1-1 significantly downregulated the expression levels of Bcl-2, 
A

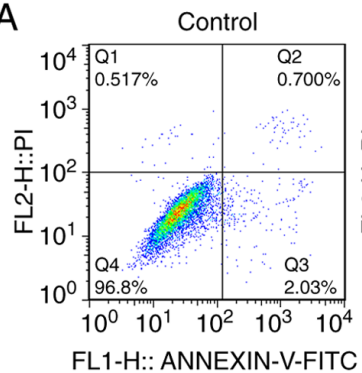

B

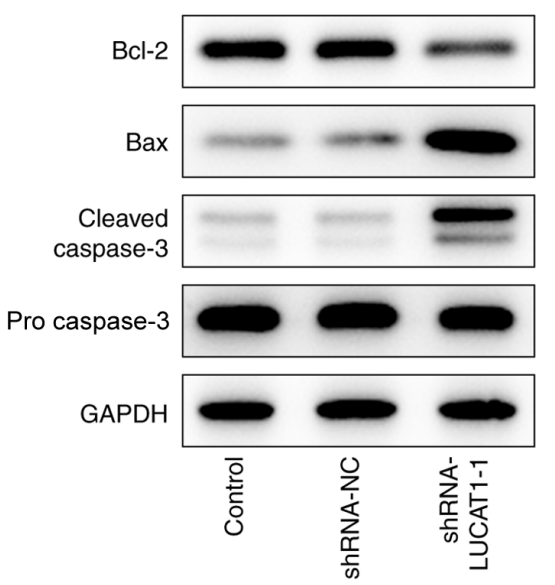

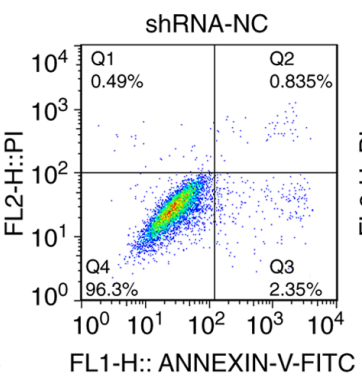

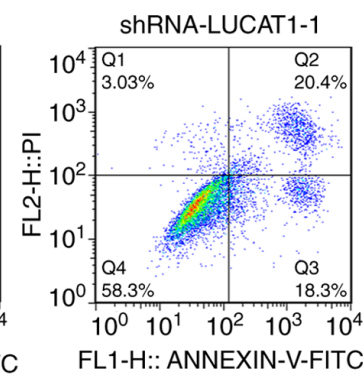

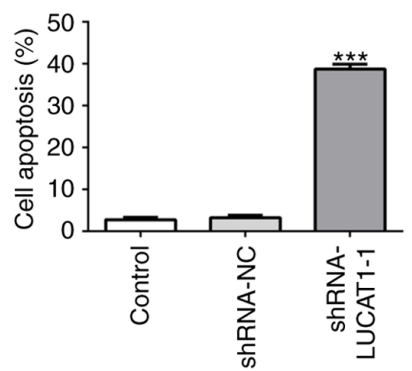
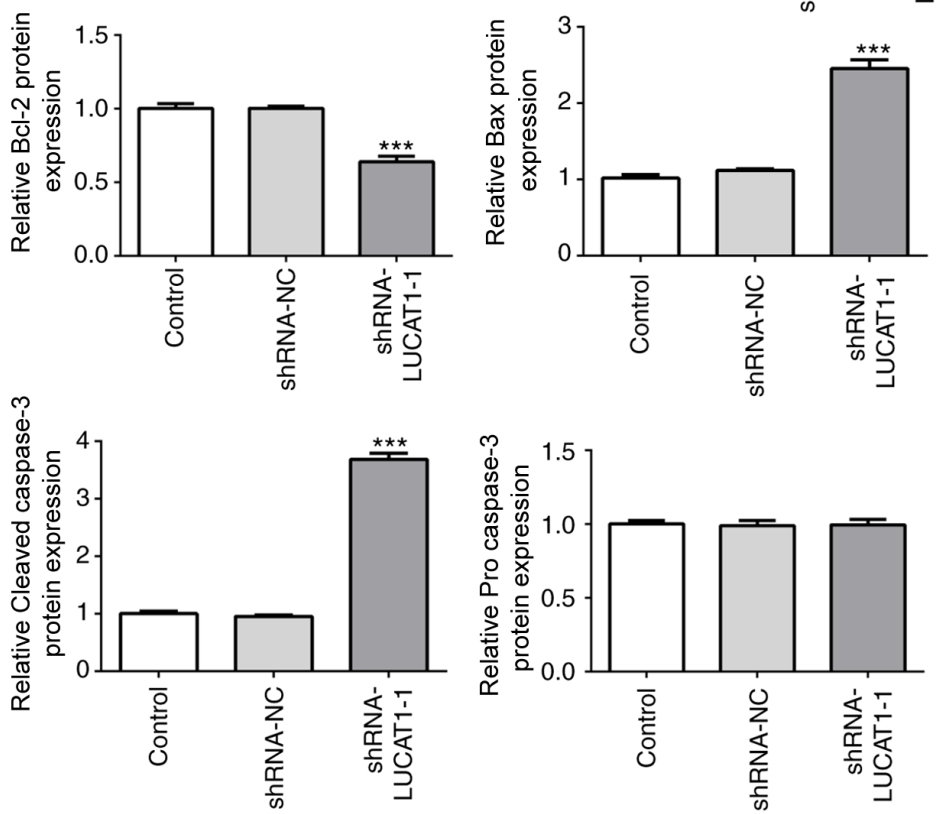

Figure 4. Inhibition of LUCAT1 increases cell apoptosis. (A) Following the genetic knockdown of LUCAT1, cell apoptosis was analyzed using flow cytometry. (B) Expression levels of the apoptosis-related proteins Bcl-2, Bax, cleaved caspase-3 and pro caspase-3 were analyzed using western blotting following the knockdown of LUCAT1. ${ }^{* * *} \mathrm{P}<0.001$, vs. shRNA-NC group. LUCAT1, lung cancer-associated transcript 1; shRNA, short hairpin RNA; NC, negative control; PI, propidium iodide.

while significantly upregulating the expression levels of Bax and cleaved caspase-3 (Fig. 4B). However, no statistical differences were observed in the expression levels of pro caspase-3 between the groups (Fig. 4B). Taken together, these findings indicated that the genetic knockdown of LUCAT1 may promote the apoptosis of LSCC cells.

Targeted inhibition of miR-493 by LUCAT1. To further investigate the molecular mechanisms underlying the role of LUCAT1 in the tumorigenesis of LSCC, the ENCORI database (http://starbase.sysu.edu.cn) was used. It was predicted that LUCAT1 directly bound with miR-493, a miRNA previously reported to inhibit tumorigenesis occurred in the 3'-UTR (29,30) (Fig. 5A).

The targeted binding between LUCAT1 and miR-493 was confirmed by the significantly reduced relative luciferase activity observed in cells co-transfected with the WT LUCAT1-Luc and miR-493-mimic. In addition, no significant differences were identified in the relative luciferase activity between the cells co-transfected with the MUT LUCAT1-Luc and miR-493-mimic or miR-493 NC (Fig. 5B). Consistent with these results, the fold enrichment of LUCAT1 co-immunoprecipitated with miR-493 was significantly increased in the LUCAT1- and miR-493-Ago2 groups compared with the IgG groups (Fig. 5C).

Notably, significantly downregulated expression levels of miR-493 were identified in LSCC cells, particularly AMC-HN-8 cells, compared with the NP69 cells (Fig. 5D), which were significantly reversed by the specific knockdown of LUCAT1 in AMC-HN-8 cells (Fig. 5E). Taken together, these results indicated the potential targeted inhibition of miR- 493 by LUCAT1 in LSCC.

miR-493 inhibition blocks the antitumorigenic effect of LUCAT1 knockdown. To determine whether LUCAT1 promoted tumorigenesis in LSCC through the targeted suppression of miR-493, miR-493 inhibitor-1 and miR-493 inhibitor-2 were co-transfected with shRNA-LUCAT1-1 into AMC-HN-8 cells. The transfection efficiency of the miR-493 inhibitors was verified using RT-qPCR (Fig. 6A). The miR-493 inhibitor-1, which exhibited an enhanced inference rate on the expression levels of miR-493, was used for subsequent assays.

The co-inhibition of miR-493 significantly blocked the inhibitory effect of shRNA-LUCAT1-1 on cell proliferation (Fig. 6B). Similarly, the inhibition of miR-493 reversed the reduction in LSCC cell proliferation induced 
A LUCAT1 :
miR-493-5p $: 3^{\prime}$

B
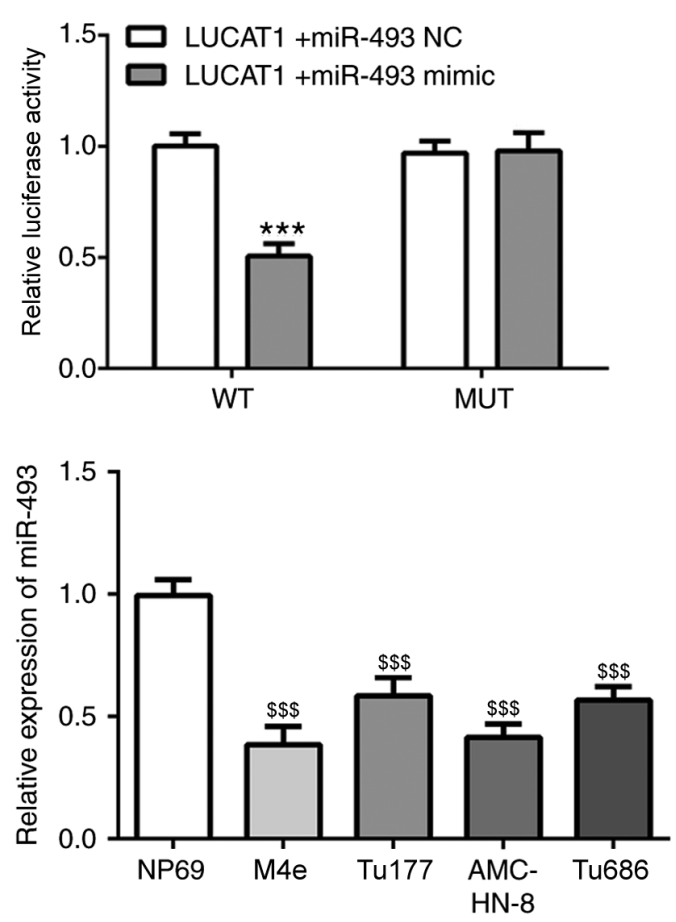

UCUUAAGAUCUG - AAUGUACAC $3^{\prime}$

| ||$::||:|\||\|| \mid$

UUACUUUCGGAUGGUACAUGUU $5^{\prime}$

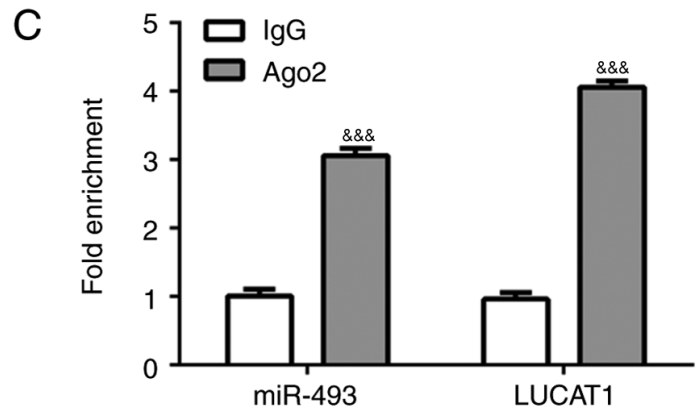

E

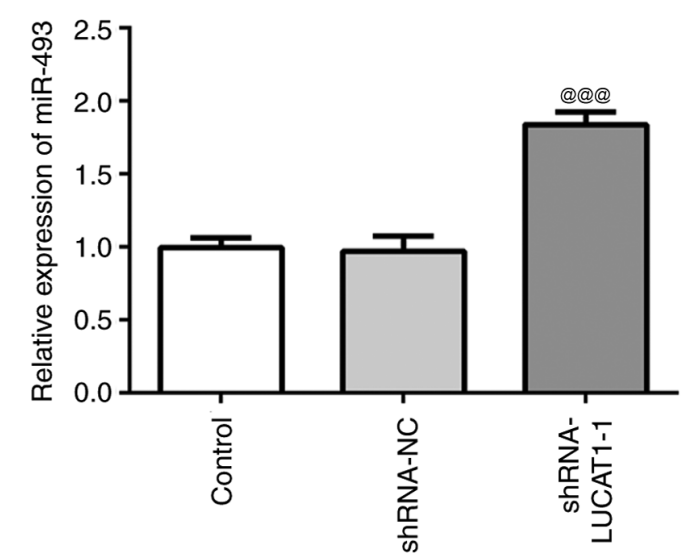

Figure 5. LUCAT1 targets miR-493. (A) Complementary binding site between the 3 ' untranslated region of LUCAT1 and miR-493 was predicted using the ENCORI. (B) Dual-luciferase reporter assay was performed to determine the relationship between LUCAT1 and miR-493. ${ }^{* * *}$ P $<0.001$, vs. shRNA-NC group. (C) Ribonucleoprotein immunoprecipitation assay was used to validate the interaction between LUCAT1 and miR-493. \&\&\&P<0.001, vs. IgG). (D) miR-493 expression levels in the normal nasopharyngeal epithelial NP69 cell line and larynx squamous cell carcinoma cells (AMC-HN-8, Tu177, Tu686 and M4e) were investigated using RT-qPCR. ${ }^{\$ \$}$ P $<0.001$ (Vs NP69). (E) miR-493 expression levels following the genetic knockdown of LUCAT1 in AMC-HN-8 cells were analyzed using RT-qPCR. ${ }^{\circledR @}{ }^{@} \mathrm{P}<0.001$, vs. shRNA-NC). LUCAT1, lung cancer-associated transcript 1; shRNA, short hairpin RNA; NC, negative control; miR, microRNA; WT, wild-type; MUT, mutant.

by shRNA-LUCAT1-1 through significantly increasing the proportion of $\mathrm{S}$ phase cells and significantly decreasing the proportion of G1 phase cells (Fig. 6C and D). Similarly, the shRNA-LUCAT1-1+miR-493 inhibitor group demonstrated significantly upregulated expression levels of CDK2 and cyclin E1, but downregulated expression levels of $\mathrm{p} 21$ compared with the cells co-transfected with the shRNA-LUCAT1-1 and miR-NC (Fig. 6E).

Furthermore,the co-transfection of shRNA-LUCAT1-1transfected AMC-HN-8 cells with the miR-493-inhibitor promoted the migration and invasion of cells (Fig. 7A-D). Consistent with these results, inhibiting miR-493 alongside LUCAT1 also significantly upregulated the expression levels of MMP2, MMP9 and VEGF-C, which were downregulated following the silencing of LUCAT1 (Fig. 7E).

In addition, the downregulation of miR-493 and LUCAT1 partially suppressed the promoting effect of shRNA-LUCAT1-1 on cell apoptosis (Fig. 8A), upregulated the expression levels of Bcl-2 and downregulated the expression levels of Bax and cleaved caspase-3 (Fig. 8B) compared with the cells co-transfected with the shRNA-LUCAT1-1 and miR-NC. Taken together, these data indicated the potential anticancer role of miR-493, which may be suppressed by LUCAT1 in LSCC.

\section{Discussion}

LSCC accounts for $\sim 90 \%$ of head and neck cancers, which comprise a heterogeneous group of cancers most commonly located in the oral cavity, oropharynx and larynx (31). LSCC is the second most common subset of head and neck SCC and poses a major threat to human health. More than 80,000 throat cancer patients die every year $(32,33)$. Patients with LSCC presenting with tumor invasion and metastasis have a poor prognosis and low five-year survival rate is only $\sim 60 \%$ (34), which may be partly attributed to the poor understanding of LSCC pathogenesis and limited treatment options. Therefore, determining the molecular mechanisms underlying the pathogenesis of LSCC may uncover novel targets for the treatment of this disease. In the present study, Experiment by genetically knocking down LUCAT1, the expression levels of LUCAT1 were discovered to be upregulated in LSCC cell lines, including AMC-HN-8, Tu177, Tu686 and M4e, promoted the proliferation, migration and invasion of the cancer cells, while inhibiting apoptosis. Moreover, the findings suggested that LUCAT1 may promote LSCC through the targeted inhibition of miR-493.

LUCAT1, previously referred to as SCAL1, comprises four exons and three introns, and is located on chromosome 
A

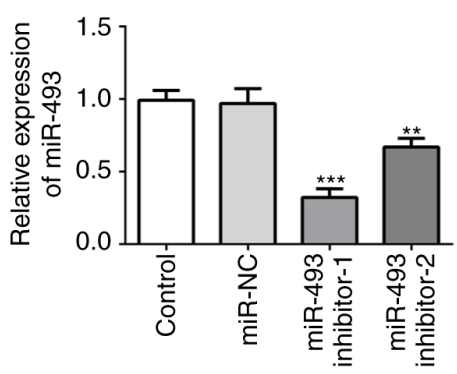

B $\rightarrow$ Control

$\rightarrow$ ShRNA-LUCAT-1

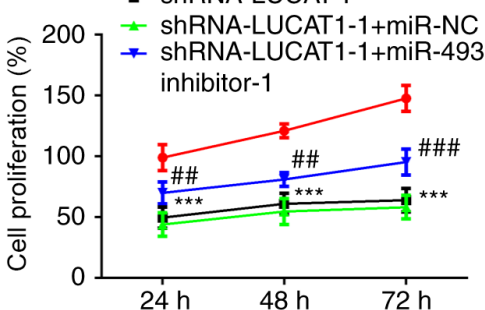

C
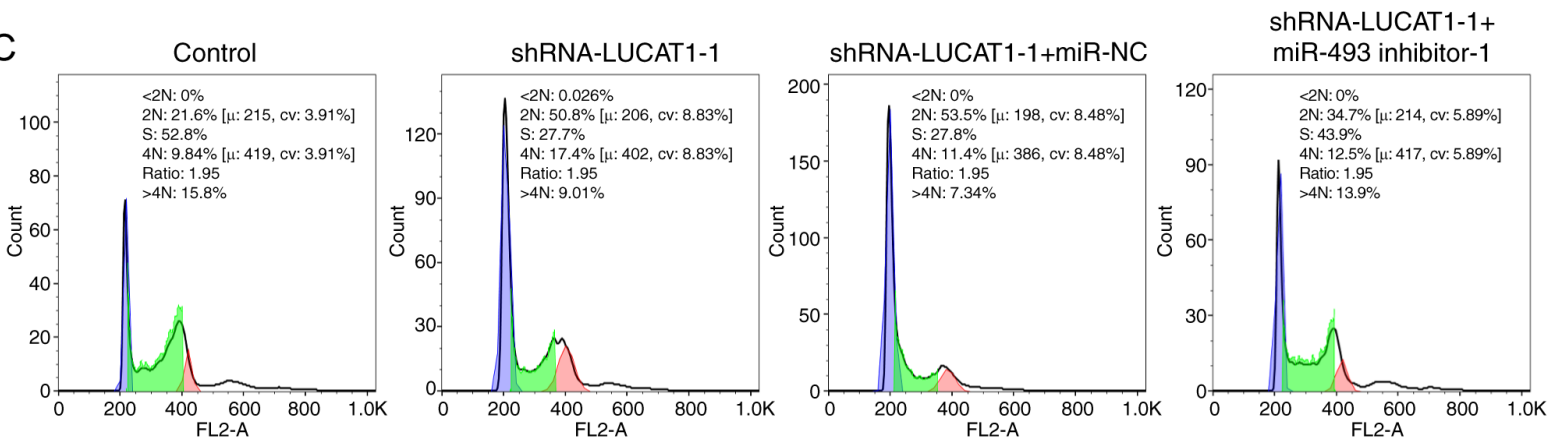

E
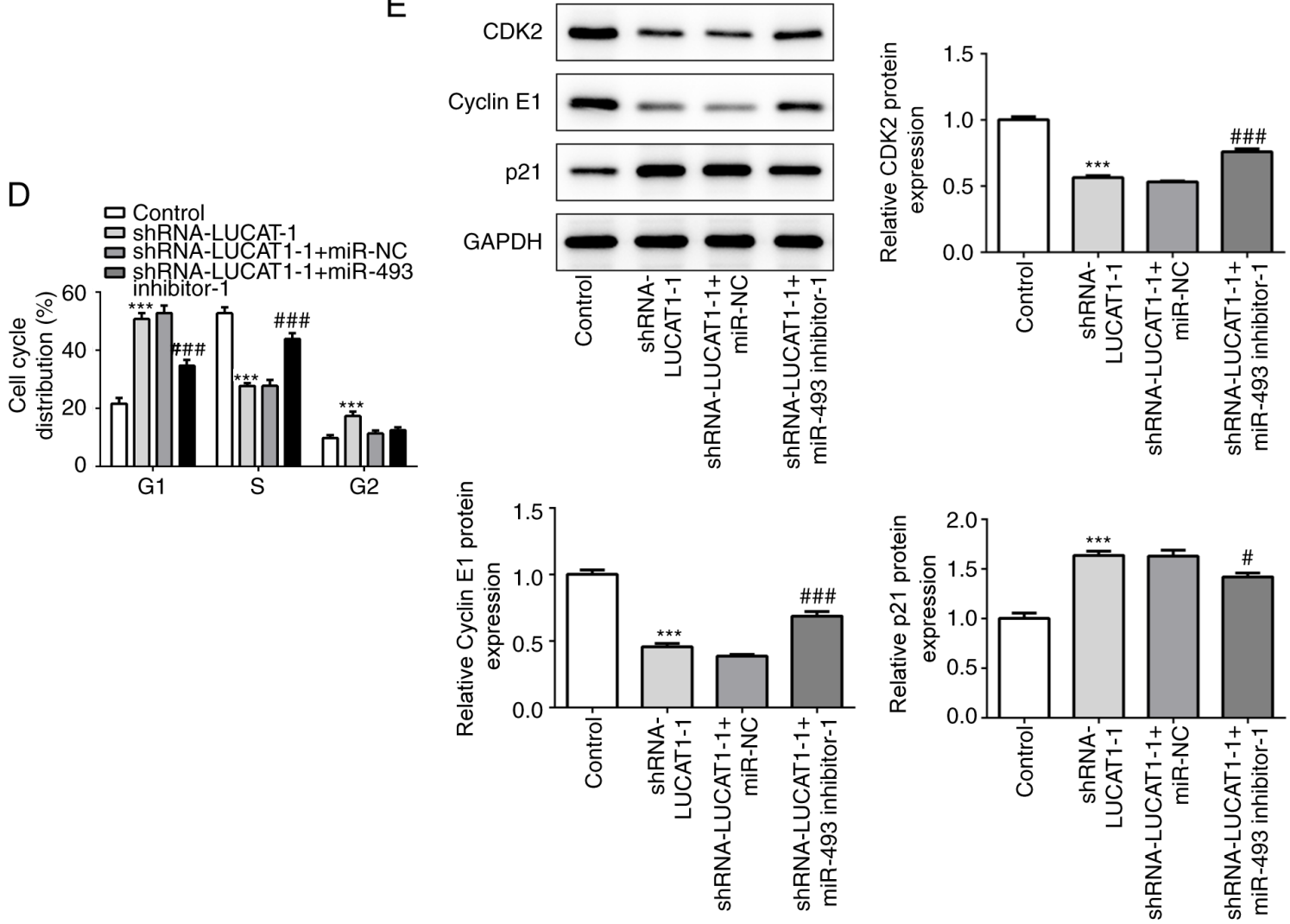

Figure 6. miR-493 silencing blocks the suppressive effect of LUCAT1 knockdown. (A) miR-493 expression levels were downregulated following the transfection of the miR-493 inhibitor-1/2 in AMC-HN-8 cells, as observed using reverse transcription-quantitative $\mathrm{PCR}$. ${ }^{* * *} \mathrm{P}<0.001,{ }^{* *} \mathrm{P}<0.01$ (vs. miR-NC). (B) Cell Counting Kit-8 assay was used to analyze the proliferation of cells following the transfection of cells with shRNA-LUCAT1-1 with or without the miR-493 inhibitor. (C) Flow cytometric analysis of the cell cycle following the transfection with shRNA-LUCAT1-1 with or without the miR-493 inhibitor. (D) Quantification of cell cycle distribution presented in part (C). (E) Expression levels of the proliferation-associated proteins CDK2, cyclin E1 and p21 were analyzed using western blotting. ${ }^{* * * *} \mathrm{P}<0.001$ vs. control; ${ }^{\#} \mathrm{P}<0.05,{ }^{\# \#} \mathrm{P}<0.01$ and ${ }^{\# \#} \mathrm{P}<0.001$, vs. shRNA-LUCAT1-1 + miR-NC. LUCAT1, lung cancer-associated transcript 1 ; shRNA, short hairpin RNA; NC, negative control; miR, microRNA.

$5 \mathrm{q} 14.3$, where it is transcriptionally regulated by nuclear factor erythroid 2-related factor (11). In previous studies, the expression levels of LUCAT1 were reported to be upregulated in several types of cancer, and served pro-tumorigenic roles, including within breast (12), colorectal (13), papillary thyroid (14), ovarian (15) and cervical cancers, among 
A
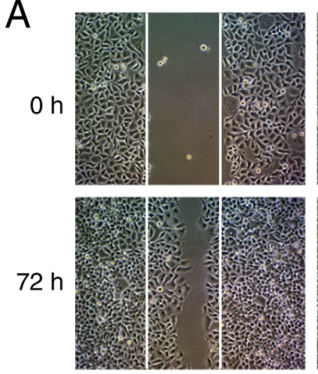

C

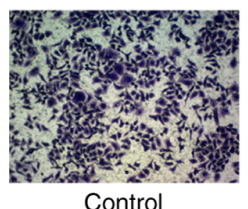

Control
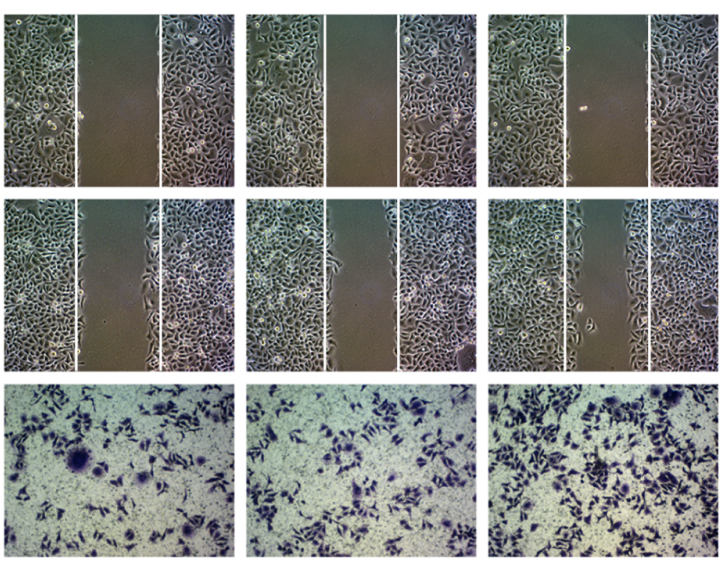

ShRNA-LUCAT1-1+ ShRNA-LUCAT1-1+ miR-NC
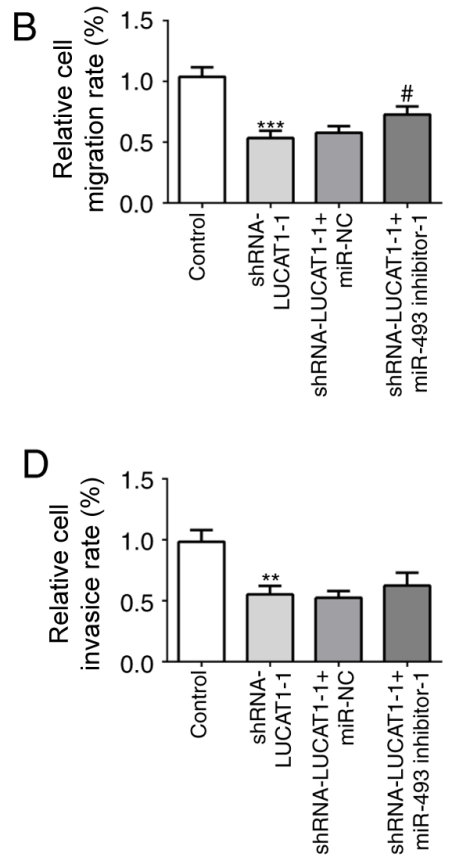

E
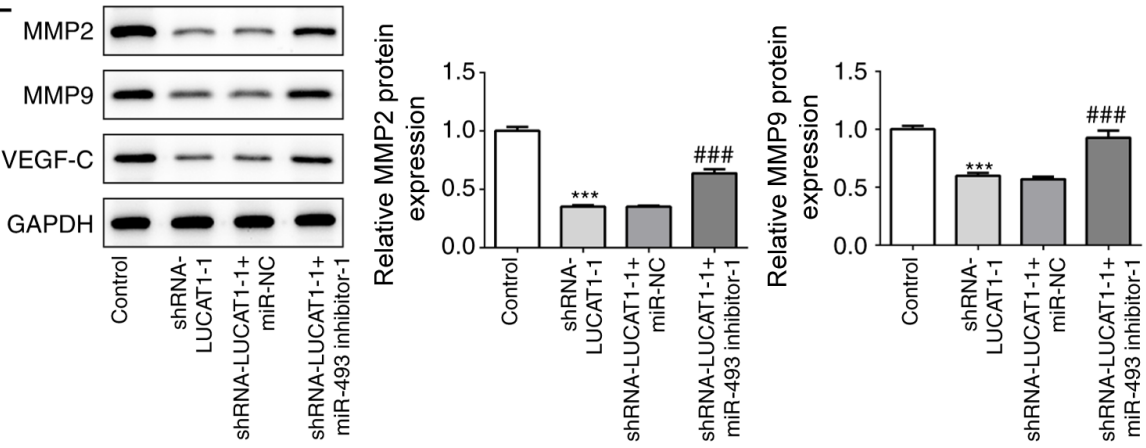

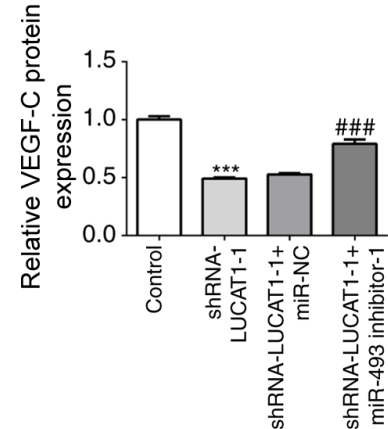

Figure 7. miR-493 silencing blocks the anti-migratory and anti-invasive effect of LUCAT1 knockdown. (A) Cell migration rate was analyzed in AMC-HN-8 cells transfected with shRNA-LUCAT1-1 with or without the miR-493 inhibitor using a wound healing assay, magnification x100. (B) Semi-quantification of the relative cell migration rate from part (A). (C) Cell invasion rate was analyzed in AMC-HN-8 cells transfected with shRNA-LUCAT1-1 with or without miR-493 inhibitor using a Transwell assay (x100). (D) Semi-quantification of the relative cell invasive rate from part (C). (E) Protein expression levels of MMP9, MMP13 and VEGF-C were analyzed using western blotting. ${ }^{* *} \mathrm{P}<0.01$ and ${ }^{* * *} \mathrm{P}<0.001$, vs. control; ${ }^{*} \mathrm{P}<0.05$, and ${ }^{\# \# \# /} \mathrm{P}<0.001$, vs. shRNA-LUCAT1-1 + miR-NC. LUCAT1, lung cancer-associated transcript 1; shRNA, short hairpin RNA; NC, negative control; miR, microRNA; MMP, matrix metallopeptidase; VEGF-C, vascular endothelial growth factor-C.

others (31). In addition, LUCAT1 was discovered to be overexpressed in oral SCC (11). Therefore, it was hypothesized that LUCAT1 may also be highly expressed and serve an important role in LSCC. In the present study, the expression levels of LUCAT1 was also upregulated in LSCC cells, while the genetic knockdown of LUCAT1 significantly suppressed the cell proliferation, migration and invasion, while promoting cell apoptosis.

The possible modulatory mechanism of LUCAT1 in LSCC was subsequently investigated. IncRNAs are involved in numerous biological processes such as regulation of transcription, translation, protein modification, and the formation of RNA-protein or protein-protein complexes $(32,33)$ and commonly act by targeted binding and regulation of proteins, mRNAs or microRNAs (32). Indeed, LUCAT1 was reported to contribute to the development of triple-negative breast cancer through promoting cell proliferation, cell cycle progression and metastasis, and attenuating cell apoptosis, and its effects were mediated by negatively modulating miR-5702 (17). Similarly, breast cancer cell stemness was discovered to be dysregulated by the LUCAT1/miR-5582-3p/transcription factor 7-like 2 axis, which increased the activity of the Wnt/ $\beta$-catenin signaling pathway (18). Moreover, LUCAT1 was reported to promote ovarian cancer progression through inhibiting miR-612 to enhance homeobox protein Hox-A13 expression levels, thereby promoting cancer cell proliferation, migration and invasion (15). In the present study, it was hypothesized that LUCAT1 may exert a role by interacting with certain miRNAs. By using the ENCORI database, the interaction between LUCAT1 and miR-493 was predicted in the 3'-UTR. Convincing evidence supports the tumor-suppressive role of miR-493; for example, miR-493 served a crucial role in tumor transformation and the survival of malignant cells, such as renal cell carcinoma (35). In addition, miR-493 has been widely reported to suppress diverse subtypes of cancer through activating or inhibiting a variety of downstream signaling cascades; for instance, miR-493 decreased the 
A
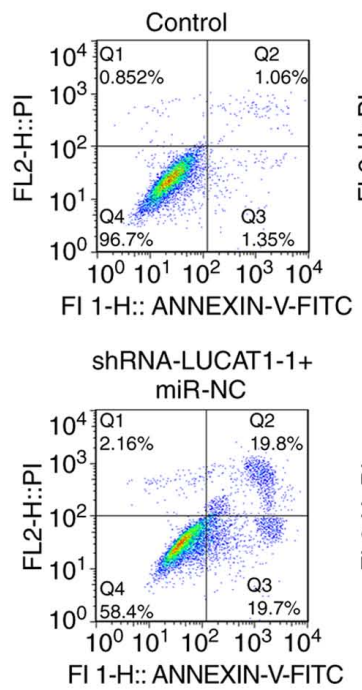

B

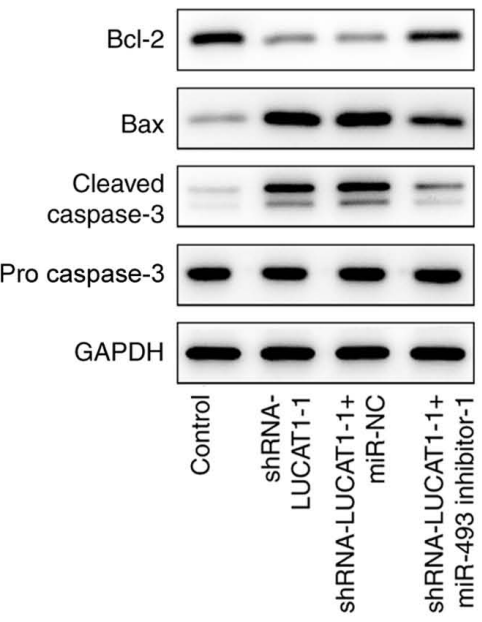

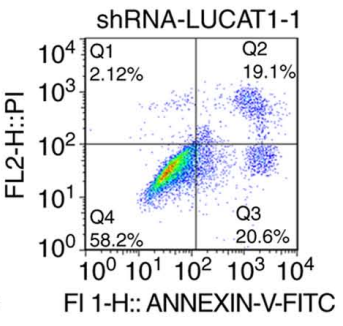
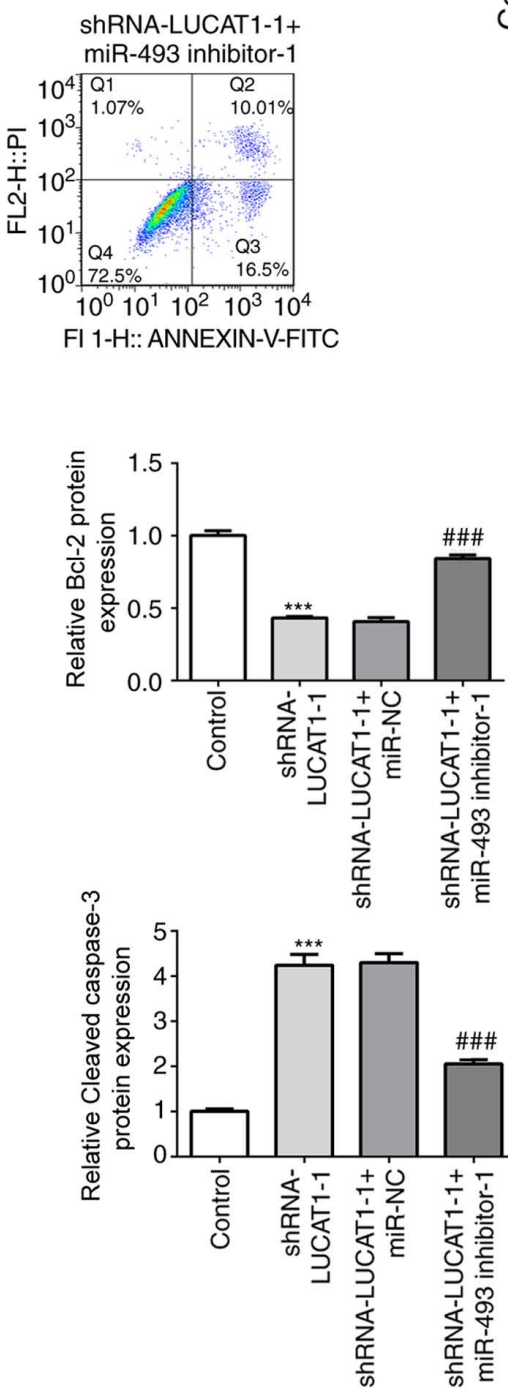
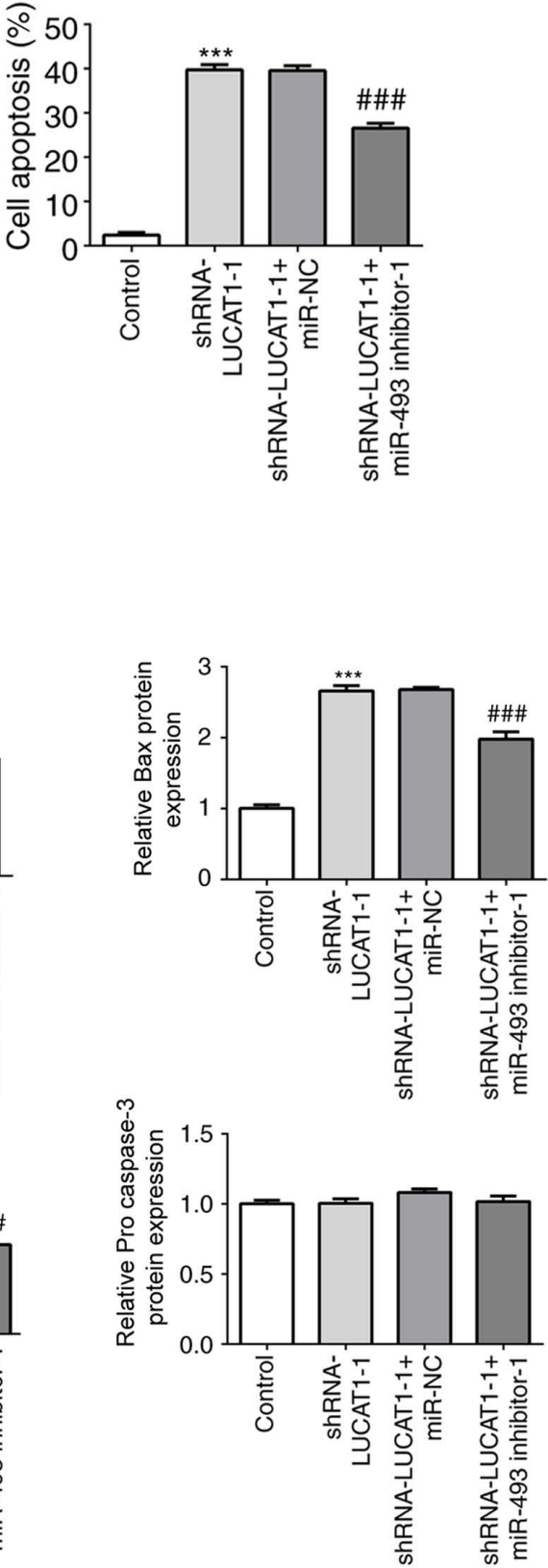

Figure 8. miR-493 silencing blocks the initiation of apoptosis induced by LUCAT1 knockdown. (A) Flow cytometric analysis of cell apoptosis of cells transfected with shRNA-LUCAT-1 with or without the miR-493 inhibitor. (B) Expression levels of the apoptosis-related proteins Bcl-2, Bax, cleaved caspase-3

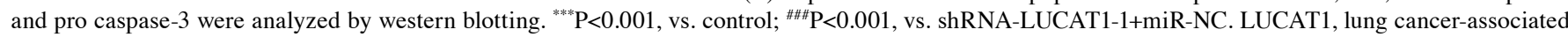
transcript 1; shRNA, short hairpin RNA; NC, negative control; miR, microRNA; PI, propidium iodide.

motility and migratory ability of human bladder cancer cells by downregulating RhoC and Frizzled-4 expression levels (36). miR-493-5p also reduced the invasiveness and tumorigenic potential of breast cancer cells via targeting $\alpha$-(1,3)-fucosyltransferase 4 (37) and suppressed hepatocellular carcinoma cell proliferation by targeting Golgi protein 73 (38). Moreover, miR-493 was reportedly involved in the carcinogenesis of osteosarcoma and hepatic cancer by targeting different signaling pathways such as Notch1, Akt, Wnt pathway $(39,40)$. In the present study, rescue experiments were performed by the significantly reduced relative luciferase activity observed in cells co-transfected with the WT
LUCAT1-Luc and miR-493-mimic, revealing that LUCAT1 facilitated LSCC tumorigenesis by inhibiting miR-493.

In conclusion, the findings of the present study suggested that LUCAT1 may promote the tumorigenesis of LSCC through the targeted inhibition of miR-493. To the best of our knowledge, this was the first study to determine the oncogenic function of LUCAT1 and detail its underlying regulatory interaction with miR-493 in LSCC cells. These results identified a novel LUCAT1/miR-493 axis and highlighted LUCAT1 and miR-493 as potential therapeutic targets for LSCC treatment. However, there are limitations to the present study. First, the study was an in vitro study and no in vivo experiments were performed 
and second, the molecular mechanisms underlying the effects of miR-493 inhibition by LUCAT1 on LSCC cell function were not fully investigated. These issues require further in-depth investigations and will be addressed in future studies.

\section{Acknowledgements}

Not applicable.

\section{Funding}

No funding was received.

\section{Availability of data and materials}

The datasets used and/or analyzed during the current study are available from the corresponding author on reasonable request.

\section{Authors' contributions}

$\mathrm{ZZ}$ designed the study and wrote the manuscript; YX performed the experiments; YL collected and analyzed the data; and SJ interpreted the data. The second draft of the manuscript was revised by ZZ and YX. All authors read and approved the final manuscript.

\section{Ethics approval and consent to participate}

Not applicable.

\section{Patient consent for publication}

Not applicable.

\section{Competing interests}

The authors declare that they have no competing interests.

\section{References}

1. Pinette A, McMichael E, Courtney NB, Duggan M, Benner BN, Choueiry F, Yu L, Abood D, Mace TA and Carson WE 3rd: An IL-15-based superagonist ALT-803 enhances the NK cell response to cetuximab-treated squamous cell carcinoma of the head and neck. Cancer Immunol Immunother 68: 1379-1389, 2019.

2. Gao P, Gong L and Wang X: Induction chemotherapy in patients with resectable laryngeal cancer: A meta-analysis. Mol Clin Oncol 9: 155-162, 2018.

3. Yang JQ, Liang Z, Wu M, Sun YM and Liu HX: Expression of p27 and PTEN and clinical characteristics in early laryngeal squamous cell carcinoma and their correlation with recurrence. Int J Clin Exp Pathol 8: 5715-5720, 2015.

4. Zheng Z, Tian R and Wang P: Roles of KAI1 and nm23 in lymphangiogenesis and lymph metastasis of laryngeal squamous cell carcinoma. World J Surg Oncol 15: 211, 2017.

5. Vijay Parshuram R, Kumar R, Bhatt MLB, Singh R, Parmar D, Gaur J, Kishan D, Saha M, Roopali, Katepogu P, et al: To investigate the affiliation of XRCC-1 Gene Arg194Trp polymorphism in alcohol and tobacco substance users and loco-regionally progressed Laryngeal squamous cell carcinoma. J Oral Biol Craniofac Res 9: 77-80, 2019.

6. Ma Z, Zhang H, Lian M, Yue C, Dong G, Jin Y, Li R, Wan H, Wang R, Wang Y, et al: SLC7A11, a component of cysteine/glutamate transporter, is a novel biomarker for the diagnosis and prognosis in laryngeal squamous cell carcinoma. Oncol Rep 38: 3019-3029, 2017.
7. He J, Zhou X, Li L and Han Z: Long noncoding MAGI2-AS3 suppresses several cellular processes of lung squamous cell carcinoma cells by regulating miR-374a/b-5p/CADM2 axis. Cancer Manag Res 12: 289-302, 2020.

8. Wu S, Ai H, Zhang K, Yun H and Xie F: Long non-coding RNA EGOT promotes the malignant phenotypes of hepatocellular carcinoma cells and increases the expression of HMGA2 via down-regulating miR-33a-5p. Onco Targets Ther 12: 11623-11635, 2019

9. Gao W, Qi CQ,Feng MG, Yang P,Liu Land Sun SH: SOX2-induced upregulation of lncRNA LINC01561 promotes non-small-cell lung carcinoma progression by sponging miR-760 to modulate SHCBP1 expression. J Cell Physiol 235: 6684-6696, 2020.

10. Thai P, Statt S, Chen $\mathrm{CH}$, Liang E, Campbell $\mathrm{C}$ and $\mathrm{Wu} \mathrm{R}$ : Characterization of a novel long noncoding RNA, SCAL1, induced by cigarette smoke and elevated in lung cancer cell lines. Am J Respir Cell Mol Biol 49: 204-211, 2013.

11. Kong Y, Feng Y, Xiao YY, Liu SC, Li XG, Yang QL, Chu WH and Liu JG: LncRNA LUCAT1 promotes rowth, migration, and invasion of oral squamous cell carcinoma by upregulating PCNA. Eur Rev Med Pharmacol Sci 23: 4770-4776, 2019.

12. Li YL, Wang XM, Qiao GD, Zhang S, Wang J, Cong YZ and Zhu SG: Up-regulated lnc-lung cancer associated transcript 1 enhances cell migration and invasion in breast cancer progression. Biochem Biophys Res Commun 521: 271-278, 2019.

13. Zhou Q, Hou Z, Zuo S, Zhou X, Feng Y, Sun Y and Yuan X: The long noncoding RNA LUCAT1 promotes CRC tumorigenesis by targeting RPL40-MDM2-p53 pathway through binding with UBA52. Cancer Sci 110: 1194-1207, 2019.

14. Luzón-Toro B, Fernández RM, Martos-Martínez JM, Rubio-Manzanares-Dorado M, Antiñolo G and Borrego S: LncRNA LUCAT1 as a novel prognostic biomarker for patients with papillary thyroid cancer. Sci Rep 9: 14374, 2019.

15. $\mathrm{Yu} \mathrm{H}, \mathrm{Xu} Y$, Zhang D and Liu G: Long noncoding RNA LUCAT1 promotes malignancy of ovarian cancer through regulation of miR-612/HOXA13 pathway. Biochem Biophys Res Commun 503: 2095-2100, 2018.

16. Dou X, Zhou Q, Wen M, Xu J, Zhu Y, Zhang S and Xu X: Long noncoding RNA FOXD2-AS1 promotes the malignancy of cervical cancer by sponging MicroRNA-760 and upregulating hepatoma-derived growth factor. Front Pharmacol 10: 1700, 2020.

17. Mou E and Wang H: LncRNA LUCAT1 facilitates tumorigenesis and metastasis of triple-negative breast cancer through modulating miR-5702. Biosci. Rep 39: BSR20190489, 2019.

18. Zheng A, Song X, Zhang L, Zhao L, Mao X, Wei M and Jin F: Long non-coding RNA LUCAT1/miR-5582-3p/TCF7L2 axis regulates breast cancer stemness via Wnt/ $\beta$-catenin pathway. J Exp Clin Cancer Res 38: 305, 2019.

19. Wang $G$, Fang $X$, Han $M$, Wang $X$ and Huang $Q$ : MicroRNA-493-5p promotes apoptosis and suppresses proliferation and invasion in liver cancer cells by targeting VAMP2. Int J Mol Med 41: 1740-1748, 2018.

20. Yasukawa K, Liew LC, Hagiwara K, Hironaka-Mitsuhashi A, Qin XY, Furutani Y, Tanaka Y, Nakagama H, Kojima S, Kato T, et al: MicroRNA-493-5p-mediated repression of the MYCN oncogene inhibits hepatic cancer cell growth and invasion. Cancer Sci 111: 869-880, 2019.

21. Zhi D, Zhao X, Dong M and Yan C: miR-493 inhibits proliferation and invasion in pancreatic cancer cells and inversely regulated hERG1 expression. Oncol Lett 14: 7398-7404, 2017

22. Liu C, Lu Z, Liu H, Zhuang S and Guo P: LncRNA XIST promotes the progression of laryngeal squamous cell carcinoma via sponging miR-125b-5p to modulate TRIB2. Biosci Rep 40: BSR 20193172, 2020

23. Li JH, Liu S, Zhou H, Qu LH and Yang JH: starBase v2.0: Decoding miRNA-ceRNA, miRNA-ncRNA and protein-RNA interaction networks from large-scale CLIP-Seq data. Nucleic Acids Res 42: D92-D97, 2014.

24. Livak KJ and Schmittgen TD: Analysis of relative gene expression data using real-time quantitative PCR and the 2(-Delta Delta $\mathrm{C}(\mathrm{T})$ ) method. Methods 25: 402-408, 2001

25. Yao Z, Li Y, Wang Z, Lan Y, Zeng T, Gong H, Zhu K, Tang H and $\mathrm{Gu}$ S: Research on anti-hepatocellular carcinoma activity and mechanism of Polygala fallax Hemsl. J Ethnopharmacol 260: 113062, 2020.

26. Garo Kyurkchiyan S, Miroslavov Popov T, Stancheva G, Rangachev J, Ivanov Mitev V, Petrova Popova D and Petrova Kaneva R: Novel insights into laryngeal squamous cell carcinoma from association study of aberrantly expressed miRNAs, lncRNAs and clinical features in Bulgarian patients. J BUON 25: 357-366, 2020 
27. Zhao J, Lv K, Li ZH, Wu J, Gao W, Wong TS, Luo J, Qin H, Wang B, Fu Q and Lei WB: Functional significance of the long non-coding RNA RP11-169D4.1 as a metastasis suppressor in laryngeal squamous cell carcinoma by regulating CDH1. Oncol Rep 38: 211-220, 2017.

28. Steuer CE, El-Deiry M, Parks JR, Higgins KA and Saba NF: An update on larynx cancer. CA Cancer J Clin 67: 31-50, 2017.

29. Anschuetz L, Shelan M, Dematté M, Schubert AD, Giger R and Elicin O: Long-term functional outcome after laryngeal cancer treatment. Radiat Oncol 14: 101, 2019.

30. Yang T and Xia S: Study of the biological function of LncRNA LUCAT1 on cervical cancer cells by targeting miR-199b-5p. Biosci Rep: Apr 30, 2020 (Epub ahead of print). doi: 10.1042/ BSR20200422.

31. Quinn JJ and Chang HY: Unique features of long non-coding RNA biogenesis and function. Nat Rev Genet 17: 47-62, 2016.

32. Peng WX, Koirala P and Mo YY: LncRNA-mediated regulation of cell signaling in cancer. Oncogene 36: 5661-5667, 2017.

33. Xu J, Chang WH, Fong LWR, Weiss RH, Yu SL and Chen $\mathrm{CH}$ : Targeting the insulin-like growth factor-1 receptor in MTAP-deficient renal cell carcinoma. Signal Transduct Target Ther 4: 2, 2019.

34. Zhang A, Zhou N, Huang J, Liu Q, Fukuda K, Ma D, Lu Z, Bai C, Watabe $\mathrm{K}$ and Mo YY: The human long non-coding RNA-RoR is a p53 repressor in response to DNA damage. Cell Res 23: 340-350, 2013.

35. Tao Y, Pinzi V, Bourhis J and Deutsch E: Mechanisms of disease: Signaling of the insulin-like growth factor 1 receptor pathway-therapeutic perspectives in cancer. Nat Clin Pract Oncol 4: 591-602, 2007.
36. Ueno K, Hirata H, Majid S, Yamamura S, Shahryari V, Tabatabai ZL, Hinoda Y and Dahiya R: Tumor suppressor microRNA-493 decreases cell motility and migration ability in human bladder cancer cells by downregulating RhoC and FZD4. Mol Cancer Ther 11: 244-253, 2012.

37. Zhao L, Feng X, Song X, Zhou H, Zhao Y, Cheng L and Jia L: miR-493-5p attenuates the invasiveness and tumorigenicity in human breast cancer by targeting FUT4. Oncol Rep 36: 1007-1015, 2016.

38. Zhao J, Xu T, Wang F, Cai W and Chen L: miR-493-5p suppresses hepatocellular carcinoma cell proliferation through targeting GP73. Biomed Pharmacother 90: 744-751, 2017.

39. Jiang Y, Zhou C, Gao Q, Yin ZQ, Wang J, Mu H and Yan J: FAM64A promotes osteosarcoma cell growth and metastasis and is mediated by miR-493. J Oncol 2020: 2518297, 2020.

40. Gailhouste L, Liew LC, Yasukawa K, Hatada I, Tanaka Y, Kato T, Nakagama H and Ochiya T: MEG3-derived miR-493-5p overcomes the oncogenic feature of IGF2-miR-483 loss of imprinting in hepatic cancer cells. Cell Death Dis 10: 553, 2019.

This work is licensed under a Creative Commons Attribution-NonCommercial-NoDerivatives 4.0 International (CC BY-NC-ND 4.0) License. 